\title{
Adaptation of photosynthesis to water deficit in the reproductive phase of a maize (Zea mays L.) inbred line
}

\author{
H.F. ZHENG ${ }^{*}$, , L.F. XIN ${ }^{* *, \#, ~ J . M . ~ G U O ~}{ }^{*}, \#$, J. MAO*, X.P. HAN*, L. JIA*, B.Y. ZHENG ${ }^{*}$, C.G. DU**, \\ R.W. ELMORE ${ }^{* * * *}$, Q.H. YANG ${ }^{*}$, , and R.X. SHAO ${ }^{*+}$ \\ Collaborative Innovation Center of Henan Grain Crops, State Key Laboratory of Wheat and Maize Crop Science, \\ College of Agronomy, Henan Agricultural University, Zhengzhou-450046, China* \\ College of Agronomy, Xinyang Agriculture and Forestry University, Xinyang-464000, China** \\ Department of Biology, Montclair State University, Montclair, NJ-07043, USA*** \\ Department of Agronomy and Horticulture, University of Nebraska-Lincoln, Lincoln-68583, USA****
}

\begin{abstract}
Photosynthesis is sensitive to water deficit (WD) stress. Maize (Zea mays L.) yield is vulnerable to water stress, especially if it occurs during the reproductive stage. In this study, the expression patterns of photosynthesis-related genes, together with photosynthetic gas-exchange and fluorescence parameters were investigated in a maize inbred line exposed to 50\% of field water capacity (moderate WD) for $15 \mathrm{~d}$ after tassel emergence. The results demonstrated that WD down-regulated expression of $p s b A, p s b B, p s b C, p s b P, p s a A, p s a B$, and $c a b$, especially at later periods of WD stress. Besides, with the increased WD stress, the steady decline in the value of photosynthesis performance index, maximum quantum yield of primary photochemistry, quantum yield for electron transport, quantum yield for the reduction of end acceptors of PSI per photon absorbed, and the efficiency of an electron beyond $\mathrm{Q}_{\mathrm{A}}{ }^{-}$that reduced PSI acceptors, and a clear increase in the J-step and I-step, K-band as well as L-band were observed. The results suggested that WD might restrict light-harvesting and electron transport. Interestingly, leaf transcript levels of $r b c L$ and $r b c S$ were up-regulated at the later stage of water stress in maize inbred line, which helped repair injury to PSII centers and maintain PSII activity (increased quantum yield of dissipation and effective antenna size of an active reaction center) under 15-d lasting WD.
\end{abstract}

Additional key words: biomass; OJIP transients; photosynthetic capacity; tassel emergence; withholding water.

\section{Introduction}

Water deficit (WD) is one of the world's most widespread climatic disasters, affecting agricultural production and therefore influencing world food security (Liu et al. 2012). Maize (Zea mays L.) is one of the most important food crops, however, it is vulnerable to WD stress. WD stress has been reported to reduce maize yield approximately by $40 \%$ or more, especially during its reproductive phase. With climate change, WD is predicted to reduce the maize yield more significantly in the future (Daryanto et al. 2016).
Photosynthesis is a complex process that involves light energy, light absorption, energy conversion, electron transfer, ATP synthesis, and $\mathrm{CO}_{2}$ fixation. Reduced photosynthetic ability decreases a yield potential (Gilbert and Medina 2016) in crops under WD. Therefore, it is important to study photosynthesis in crops under stress to meet future global food demand (Long et al. 2015). Many studies have shown that WD could cause changes in photosynthesis at physiological and molecular levels. In addition to stomatal limitations, other photosynthetic processes may also reflect co-limited photosynthetic rate $\left(P_{\mathrm{N}}\right)$. Under moderate or severe WD stress, nonstomatal

Received 10 May 2017, accepted 7 February 2018.

${ }^{+}$Corresponding author; phone:+86-371-56990239, e-mail: shaoruixin@henau.edu.cn; yangqinghua@henau.edu.cn

Abbreviations: : ABS/RC - effective antenna size of an active reaction center; Chl - chlorophyll; $C_{\mathrm{i}}$ - intercellular $\mathrm{CO}_{2}$ concentration; $\mathrm{CK}$ - control; $\mathrm{DI}_{\mathrm{O}} / \mathrm{RC}$ - trapped energy flux per reaction center; $\mathrm{FC}$ - field capacity; $\mathrm{F}_{0}$ - minimal fluorescence yield of the dark-adapted state; $\mathrm{F}_{\mathrm{M}}$ - maximal fluorescence yield of the dark-adapted state; $g_{\mathrm{s}}-$ stomatal conductance; OEC - oxygen-evolving complex; $P_{\mathrm{N}}-$ net photosynthetic rate; $\mathrm{PI}_{\mathrm{ABS}}$ - performance index for energy conservation from photons absorbed by PSII to the reduction of intersystem electron acceptors; RCs - reaction centers; $\mathrm{T}$ - days of treatment; $\mathrm{TR}_{0} / \mathrm{RC}$ - quantum yield of dissipation; $\mathrm{WD}$ - water deficit; $\mathrm{W}_{\mathrm{OK}}-$ relative variable fluorescence for the normalization between $\mathrm{F}_{\mathrm{O}}$ and $\mathrm{F}_{300 \mathrm{us}} ; \mathrm{W}_{\mathrm{OJ}}$ - relative variable fluorescence for the normalization between $\mathrm{F}_{\mathrm{O}}$ and $\mathrm{F}_{\mathrm{J}} ; \mathrm{V}_{\mathrm{OP}}$ - relative variable fluorescence at any phase of the fluorescence induction curve; $\varphi_{\mathrm{P}_{\mathrm{o}}}-$ maximum quantum yield of primary photochemistry; $\varphi_{\mathrm{E} o}$ - quantum yield for electron transport; $\varphi_{\mathrm{Ro}}-$ quantum yield for the reduction of end acceptors of PSI per photon absorbed; $\psi_{\mathrm{O}}$ - the efficiency of an electron beyond $\mathrm{Q}_{\mathrm{A}}-$ that reduced PSI acceptors.

Acknowledgements: This research was financially supported by Open Foundation of CAAS/Key Laboratory of Crop Water Use and Regulation, Ministry of Agriculture (FIRI2016-01-02), Key Scientific and Technological Projects of Henan Province (152102110069).

\# These authors contributed equally to this work. 
limitations became crucial (Ye et al. 2008, Mo et al. 2016), the activity of enzymes related to the Calvin cycle were down-regulated, and the photosynthetic rate was restricted. After long-term WD stress, the performance of PSII is reduced and electron transport is blocked, resulting in down-regulation of photosynthesis in mulberry and wheat leaves (Guha et al. 2013, Živčák et al. 2013, Ye et al. 2013) in response to the adverse environment. Furthermore, at the molecular level, WD affects the levels of some mRNAs and proteins of PSII and PSI (Yuan et al. 2005). For example, transcription rates of $p s b A$ and $c a b$, which encode the D1 and the LHCII of PSII, respectively, are reduced dramatically under osmotic stress in barley and wheat cultivars, further reducing electron transport (Yuan et al. 2005, Liu et al. 2006). The light-harvesting proteins, CP47 and CP43, as well as psaB of PSI are down-regulated under WD stress, thereby reducing the activities of the PSII electron transport and light-harvesting complexes (Muhammad Salman et al. 2016). The psbP protein (23 $\mathrm{kDa}$ ) is essential for the regulation and stabilization of PSII (Ifuku et al. 2005), decreasing amounts of expressed $p s b P$ protein led to the progressive loss of variable fluorescence and a marked decrease of $\mathrm{F}_{\mathrm{V}} / \mathrm{F}_{\mathrm{M}}$ (Yi et al. 2007). Although WD could result in damage to the photosynthetic apparatus, plants have evolved several mechanisms to protect it from injury. For example, up-regulation of $r b c L$ and $r b c S$ to maintain photosynthesis capacity has been reported (Fu et al. 2007, Xu et al. 2013). However, down-regulation of $r b c L$ and $r b c S$ (Seki et al. 2002, Yuan et al. 2005, Hansen et al. 2013), Rubisco, and other enzymes involved in photosynthesis (Parry et al. 2002) have been reported. These contrasting results may reflect the fact that photosynthetic responses to WD stress are influenced by species, stress intensity, and stress duration (Živčák et al. 2013).

Research has indicated that the PSII photochemical efficiency of maize is inhibited by WD during the reproductive phase, resulting in a higher rate of kernel and ear abortion (Kakumanu et al. 2012). Furthermore, under long-term WD conditions, a dramatic decrease in photosynthetic activity led to a more significant decline of growth and yield (Hayano-Kanashiro et al. 2009, Guha et al. 2013, Anjum et al. 2016). Photosynthesis genes play an important role in adaptation of photosynthesis to WD in the reproductive phase. But there are few studies on expression of photosynthesis-related genes in response to long-term WD stress. Therefore, in this study, we assessed chlorophyll (Chl) $a$ fluorescence measurements combined with leaf transcript levels of genes related to photosynthesis processes (i.e., light-harvesting, electron transport, and carbon assimilation) involved in the WD-stress response. The results of this study provide insight into photosynthetic regulatory mechanisms that act in response to WD stress in the reproductive stage of maize.

\section{Materials and methods}

Plant materials and growth conditions: This study was conducted as a potted plant experiment under an autorain shelter from June 24 to October 3, 2015 at Henan Agricultural University in Zhengzhou, China. Experi- ments were performed using maize (Zea mays L.) inbred line HZ4, which was germinated in plastic trays containing a soil:compost (2:3) mixture. One week after germination, uniform seedlings with a single stem were selected and transplanted into plastic pots $(35 \mathrm{~cm}$ diameter $\times 30 \mathrm{~cm}$ high) filled with $20 \mathrm{~kg}$ air-dried clay loam [soil water content of $36.4 \% ; 8.1 \mathrm{~g}$ (organic matter) $\mathrm{kg}^{-1} ; 61.8 \mathrm{mg}(\mathrm{N})$ $\mathrm{kg}^{-1} ; 22.4 \mathrm{mg}(\mathrm{P}) \mathrm{kg}^{-1} ; 134.1 \mathrm{mg}(\mathrm{K}) \mathrm{kg}^{-1}$. These plants were treated with $12 \mathrm{~g}$ of compound $\mathrm{N}-\mathrm{P}_{2} \mathrm{O}_{5}-\mathrm{K}_{2} \mathrm{O}$ fertilizer $\left(\mathrm{N}, 25 \% ; \mathrm{P}_{2} \mathrm{O}_{5}, 18 \% ; \mathrm{K}_{2} \mathrm{O}, 12 \%\right)$. Finally, $3 \mathrm{~g}$ of urea was added to each pot at the bell stage (Zhao et al. 2013).

WD stress: Maize plants were watered daily to $75 \%$ field capacity (FC) before stress application. After tassel emergence, plants were either watered at $75 \% \mathrm{FC}$ (control, $\mathrm{CK}$ ) or subjected to moderate WD stress at $50 \% \mathrm{FC}$ (Zhang et al. 2015) for $15 \mathrm{~d}$. Each pot was weighted at about 18:00 h every day to determine whether the water was needed for maintaining the required water stress levels (Zheng and Yan 2006). Maize plants were then sampled after $0,5,7,9,11,13$, and $15 \mathrm{~d}(\mathrm{~T})$ following initiation of WD stress to examine leaf gas exchange and Chl $a$ fluorescence parameters. Healthy and undamaged ear leaves were excised from sample plants, frozen in liquid $\mathrm{N}_{2}$, and stored at $-80^{\circ} \mathrm{C}$ for further analysis. After $15 \mathrm{~d}$, WD-treated maize plants were restored to the control level of watering. The shoot biomass of CK and WD plants were measured after maize plants were harvested. Four biological replicates of each treatment were measured for physiological parameters, and three biological replicates were collected for measuring the expression patterns of photosynthesis-related genes at T0, T5, T7, T9, T11, T13, and $\mathrm{T} 15$.

Leaf gas-exchange parameters: Photosynthetic rates $\left(P_{\mathrm{N}}\right)$, stomatal conductance $\left(g_{\mathrm{s}}\right)$, and intercellular $\mathrm{CO}_{2}$ concentration $\left(C_{\mathrm{i}}\right)$ of the ear leaves of maize plants were measured between 11:00-13:00 $\mathrm{h}$ with a hand-held leaf photosynthesis system (CI-340, CID, Camas, WA, USA) at T0, T5, T7, T9, T11, T13, and T15 according to the manufacturer's instructions (Syuhada et al. 2014).

OJIP transient analysis: Chl a fluorescence OJIP transients were measured using a plant efficiency analyzer (Handy-PEA, Hansatech Instruments Ltd., UK) according to the methods reported by (Zhang et al. 2011) at 11:0011:30 h at T0, T5, T7, T9, T11, T13, and T15 using the same leaves used for leaf gas-exchange parameters. Clips were attached to maize plants, allowed to adapt under dark conditions for $25 \mathrm{~min}$, and then used for 5-min measurements (Zhang et al. 2011). The rise in OJIP transients was analyzed using the JIP-test (Panda et al. 2006, Strasser et al. 2010). Chl a fluorescence transients were doublenormalized (between $\mathrm{F}_{\mathrm{O}}$ and $\mathrm{F}_{\mathrm{M}}$ ) and presented as the kinetics of relative variable fluorescence at any time, $\mathrm{V}_{\mathrm{OP}}$ $=\left(F_{T}-F_{O}\right) /\left(F_{M}-F_{O}\right)$. Subsequent normalizations and subtractions were carried out to determine the different kinetic profiles, using the following formula: $\triangle V_{\mathrm{OP}}=$ $\mathrm{V}_{\mathrm{OP}}$ (treatment) - $\mathrm{V}_{\mathrm{OP}}$ (control) (Strasser et al. 2007). The relative fluorescence between steps $\mathrm{O}$ and $\mathrm{K}\left[\mathrm{W}_{\mathrm{OK}}=\right.$ 


\begin{tabular}{|c|c|c|c|}
\hline Gene & Gene description & Sequence $\left[5^{\prime}-3^{\prime}\right]$ & $\operatorname{Tm}\left[{ }^{\circ} \mathrm{C}\right]$ \\
\hline \multirow[t]{2}{*}{ actin } & & F: CTGAACCCCAAGGCAAACA & 59.0 \\
\hline & & R: ACTGGCGTACAGGGAAAGAA & 57.3 \\
\hline \multirow[t]{2}{*}{$p s b A$} & PSII protein D1 & F: GGTATTCGTGAGCCTGTTTCTG & 59.1 \\
\hline & & R: GACCGCCATTGTATAACCATTC & 58.9 \\
\hline \multirow[t]{2}{*}{$p s b B$} & PSII CP47 chlorophyll apoprotein & F: AGGCGTAACGGTGGAGTTCTAT & 59.9 \\
\hline & & R: GCAAAGGTAGCATGACCAAAAG & 59.5 \\
\hline \multirow[t]{2}{*}{$p s b C$} & PSII CP43 chlorophyll apoprotein & F: TTTTGGGACCTTCGTGCTC & 58.2 \\
\hline & & R: ACAAAATGGGAGGTCGCTAA & 57.4 \\
\hline \multirow[t]{2}{*}{$p s b P$} & Chloroplast oxygen-evolving complex/thylakoid lumenal protein & F: TCAGGCTCCAAACTACACCAG & 57.7 \\
\hline & & R: CTATCCTTCATCTTTTCCCACC & 57.4 \\
\hline \multirow[t]{2}{*}{ psaA } & PSI P700 apoprotein A1 & F: TCACCACTTAGCGGGATTATTA & 57.3 \\
\hline & & R: TTAGGATCAACCCCAGCGTC & 59.8 \\
\hline \multirow[t]{2}{*}{$\operatorname{psaB}$} & PSI P700 apoprotein A2 & F: ACGCCGAATCTCGTCTGAAT & 59.6 \\
\hline & & R: CCGGGAATAGCAACATGAACT & 59.3 \\
\hline \multirow[t]{2}{*}{$r b c L$} & Rubisco large subunit & F: CCGTTTCGTCTTTTGTGCC & 58.9 \\
\hline & & R: TGCGGTGAATCCTCCTGTT & 58.3 \\
\hline \multirow[t]{2}{*}{$r b c S$} & Rubisco small subunit & F: CGCTACTGGACCATGTGGAA & 59.0 \\
\hline & & R: ACTGCGTCTGCTTGATGTTGT & 58.1 \\
\hline \multirow[t]{2}{*}{$c a b$} & Light harvesting chlorophyll $a / b$ binding protein & F: CAACATGATGGATGGCTTCTACA & 59.8 \\
\hline & & R: GCTCGCATTGGAACGATTTT & 60.0 \\
\hline \multirow[t]{2}{*}{ rca } & Ribulose-1,5-bisphosphate carboxylase/oxygenase & F: CAACATGATGGATGGCTTCTACA & 60.1 \\
\hline & & R: GCTCGCATTGGAACGATTTT & 60.3 \\
\hline
\end{tabular}

Note: The primers were designed according to sequences homology among published sequences of various photosynthetic genes in maize in GeneBank in our study. F - forward primer; $\mathrm{R}$ - reverse primer.

$\left.\left(\mathrm{F}_{\mathrm{T}}-\mathrm{F}_{\mathrm{O}}\right) /\left(\mathrm{F}_{\mathrm{K}}-\mathrm{F}_{\mathrm{O}}\right)\right]$, and between steps $\mathrm{O}$ and $\mathrm{J}\left[\mathrm{W}_{\mathrm{OJ}}=\right.$ $\left.\left(\mathrm{F}_{\mathrm{T}}-\mathrm{F}_{\mathrm{O}}\right) /\left(\mathrm{F}_{\mathrm{J}}-\mathrm{F}_{\mathrm{O}}\right)\right]$ were normalized and displayed as $\triangle \mathrm{W}_{\mathrm{OK}}=\mathrm{W}_{\mathrm{OK}}(\mathrm{WD})-\mathrm{W}_{\mathrm{OK}}(\mathrm{CK})$ and $\triangle \mathrm{W}_{\mathrm{OJ}}=\mathrm{W}_{\mathrm{OJ}}(\mathrm{WD})$ - $\mathrm{W}_{\mathrm{OJ}}(\mathrm{CK})$ at different treatment times, which made the L-band $\left[\left(\mathrm{F}_{100 \mu \mathrm{s}}-\mathrm{F}_{\mathrm{O}}\right) /\left(\mathrm{F}_{300 \mu \mathrm{s}}-\mathrm{F}_{\mathrm{O}}\right)\right]$ and K-band $\left[\left(\mathrm{F}_{300 \mu \mathrm{s}}-\right.\right.$ $\left.\left.\mathrm{F}_{\mathrm{O}}\right) /\left(\mathrm{F}_{\mathrm{J}}-\mathrm{F}_{\mathrm{O}}\right)\right]$ visible, respectively (Jiang et al. 2006, Meng et al. 2016, Sarkar and Ray 2016). The phases of OJIP curves reflect the different reduction processes of the electron transport chain (Strasser et al. 2004, Schansker et al. 2005). The J-step, I-step, and IP phase of OJIP transients correlate with the redox states of the primary quinone acceptor of PSII $\left(\mathrm{Q}_{\mathrm{A}}\right)$, the redox states of plastoquinone, and the redox states of end acceptors of PSI, respectively (Lin et al. 2009). The OJIP Chl fluorescence transient is not only due $\mathrm{Q}_{\mathrm{A}}$ reduction and the JIP test, other processes also contribute to the transients (Lazár 2006). In order to gain further insights into the mechanisms underlying WDinduced changes, we further quantified OJIP fluorescence transients in PSII to determine structural and functional information. Descriptions and equations for all parameters (Strasser et al. 2010, Stirbet 2011, Goltsev et al. 2012, Gomes et al. 2012) are shown in Table 1S (supplement).

RNA extraction and real-time RT-PCR: Real-time RTPCR was used to determine changes in gene expression. Total RNA and cDNA synthesis were conducted using RNAiso Plus and the PrimeScript ${ }^{\mathrm{TM}}$ RT Reagent kit with gDNA Eraser (AMV First Strand cDNA Synthesis kit) (Sangon Biotech Co., Ltd, Shanghai, China) according to the manufacturer's protocols. Quantitative real-time
(qRT)-PCR was performed using the $S G$ Fast $q P C R$ Master Mix (2×) kit (BBI) on a Light Cycler 480 machine (Roche Diagnostics, Germany) according to the manufacturer's instructions. The qRT-PCR amplification mixture $(20 \mu \mathrm{l})$ contained $2 \mu \mathrm{l}$ of cDNA, $10 \mu \mathrm{l}$ of SYBR Premix Ex Taq II (Tli RNaseH Plus), and $0.4 \mu \mathrm{l}$ of forward and reverse primers. Actin was used as a reference gene for data normalization. The gene ID of actin was 100281811 . Relative transcript levels were calculated using the $2^{-\Delta \Delta \mathrm{Ct}}$ method. Each data point is expressed as the average \pm SD of three independent replicates. Special primers were designed using Primer Premier 5.0. Primers used to determine the transcript levels of $p s b A, p s b B, p s b C, p s b P, p s a A$, $p s a B, r b c L, r b c S, c a b$, and $r c a$ are shown in the text table (on the top of the page).

Statistical analysis: Data was analyzed using one-way analysis of variance (ANOVA) in SPSS (version 19.0) and Duncan's multiple range test to determine significant $(p<0.05$ or $p<0.01)$ differences between treatments. Data were expressed as averages \pm standard deviation (SD) of independent replicates.

\section{Results}

Effect of WD stress on leaf gas-exchange parameters: Continuous WD stress resulted in loss of leaf water and a $23 \%$ decline of shoot biomass compared with CK (Table 1), simultaneously, the maize yield decreased to $18.93 \mathrm{~g}$ per plant compared with the CK conditions. In addition, we 
Table 1 . The maize yield and shoot dry mass after postharvest under the control conditions (CK) and continuous water deficit (WD). Data are the means \pm standard deviation (SD) of four replicates. ${ }^{*}$ and ${ }^{* *}$ represent significant differences between CK and WD treatments according to Duncan's multiple range test at $p<0.05$ and $p<0.01$, respectively.

\begin{tabular}{lll}
\hline Treatment & Yield [g per plant] & Shoot dry mass [g per plant] \\
\hline CK & $71.2 \pm 0.37$ & $189.9 \pm 17.5$ \\
WD & $50.3 \pm 0.34^{* *}$ & $146.0 \pm 12.4^{*}$ \\
\hline
\end{tabular}

found that continuous WD stress conditions could result in plant phenotypic alterations (Fig. 1S, supplement), including reduced plant height and inhibited growth compared to corresponding controls under continuous WD stress conditions. This might be why the postharvest shoot biomass after the WD treatment was significantly lower than that of CK. In addition, the exposure of maize to progressive drought stress resulted in a decrease in relative water contents compared with the CK conditions, and the decrease was enhanced with increased drought duration. The relative water contents of maize ear leaf dropped at T15 from 92.3 (T0) to $77.5 \%$ (Fig. $1 A$ ).

There were no significant differences in $P_{\mathrm{N}}$ between treatments under the $\mathrm{CK}$ conditions. The gs was improved with increasing time under $\mathrm{CK}$ conditions; at T9, T11, $\mathrm{T} 13$, and $\mathrm{T} 15$, the values were all significantly higher than that of T0 and T5. However, under the WD, $P_{\mathrm{N}}$ and $g_{\mathrm{s}}$ at T5 were not significantly different from T7, but they were significantly different from T9, T11, T13, and T15. Compared with corresponding CK, WD samples at T5, T7, T9, T11, T13, and T15 exhibited reductions of 3.7, $9.2,15.4,24.5,33.8$, and $41.7 \%$ in $P_{\mathrm{N}}$, respectively, with concurrent reductions of $10.4,12.7,27.6,39.5,53.7$, and $57.9 \%$ in $g_{\mathrm{s}}$, respectively (Fig. $1 B, C$ ). The $C_{\mathrm{i}}$ values of WD-stressed maize exhibited less severe reductions compared with the corresponding $\mathrm{CK}$, with values declining by $8.2,9.4,3.7,5.6,6.5$, and $6 \%$ at T5, T7, T9, T11, T13, and T15, respectively (Fig. $1 D$ ).

Effect of WD on OJIP transients and PSII parameters: In order to analyze further the photosynthesis adaptation, OJIP transients were measured. Chl $a$ fluorescence transient curves ( $\mathrm{V}_{\mathrm{OP}}$ curves) exhibited a typical polyphasic rise during the basic steps of O-J-I-P (Fig. 2). Heterogeneity in the OJIP transients significantly increased with WD treatment (Fig. 2). However, the fluorescence intensity showed no significant changes at different treatment times in the $\mathrm{CK}$ group (Fig. 2). Under the WD, the relative fluorescence of $\mathrm{L}$ $(0.15 \mathrm{~ms})$ and $\mathrm{K}(0.3 \mathrm{~ms})$ bands as well as the value of the $\triangle \mathrm{V}_{\mathrm{OK}}$ and $\triangle \mathrm{V}_{\mathrm{OJ}}$, increased with prolonged WD duration,

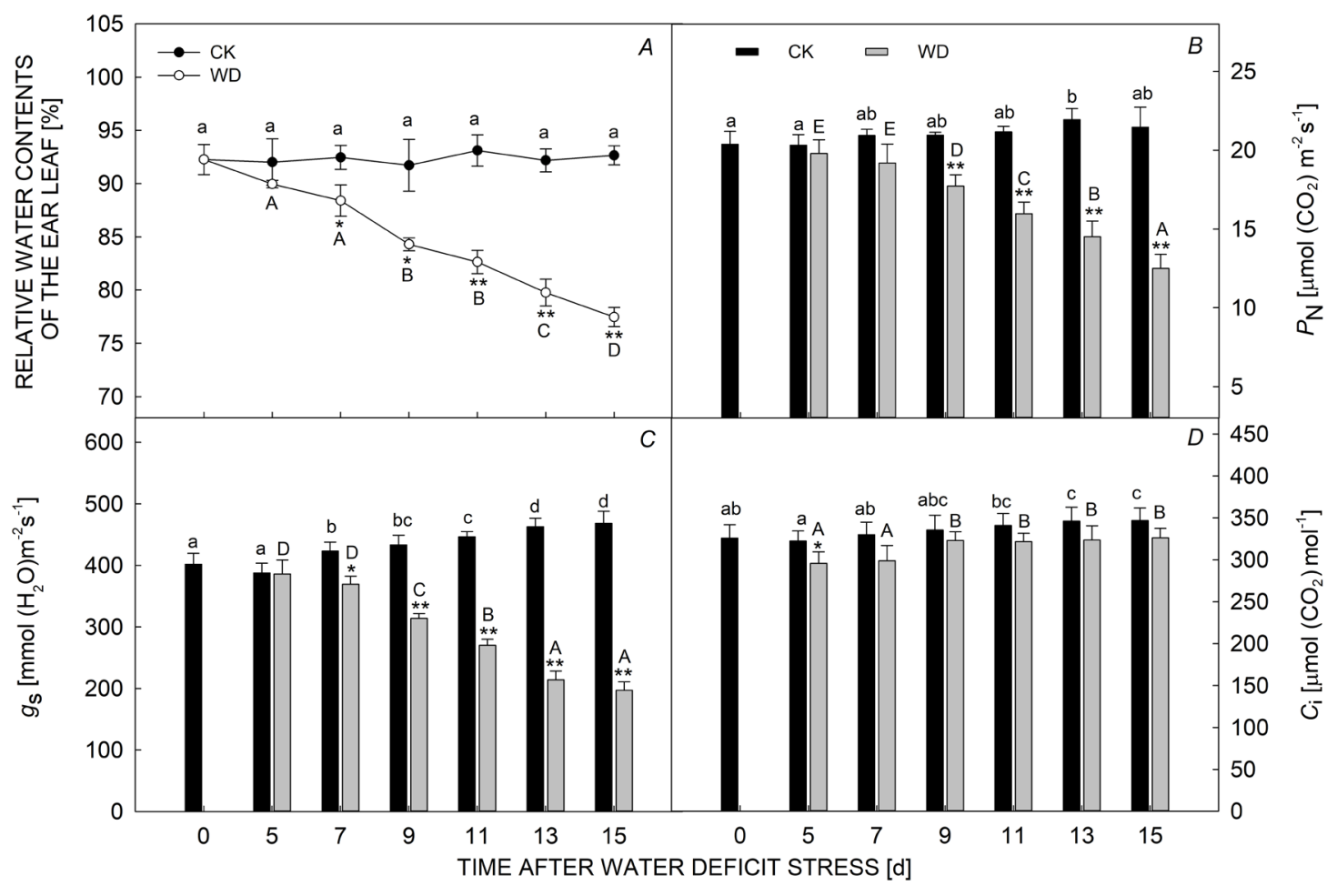

Fig. 1. Effects of continuous water-deficit stress on $(A)$ ear leaf relative water content $(B)$ photosynthetic rate $\left(P_{\mathrm{N}}\right),(C)$ stomatal conductance $\left(g_{\mathrm{s}}\right)$, and $(D)$ intercellular $\mathrm{CO}_{2}$ concentration $\left(C_{\mathrm{i}}\right)$ of reproductive phase of maize. Maize was treated as follows: the control conditions (CK) and continuous water deficit (WD). T0, T5, T7, T9, T11, T13, and T15 represent 0, 5, 7, 9, 11, 13, and 15 d of WD stress, respectively. Data are the mean \pm standard deviation (SD) of four replicates. ${ }^{*}$ and ${ }^{* *}$ represent significant differences between CK and WD stress treatments according to Duncan's multiple range test at $p<0.05$ and $p<0.01$, respectively, the capital letters and lowercase letters represent significant differences between water deficit groups and control groups, respectively, according to Duncan's multiple range test at $p<0.05$. 


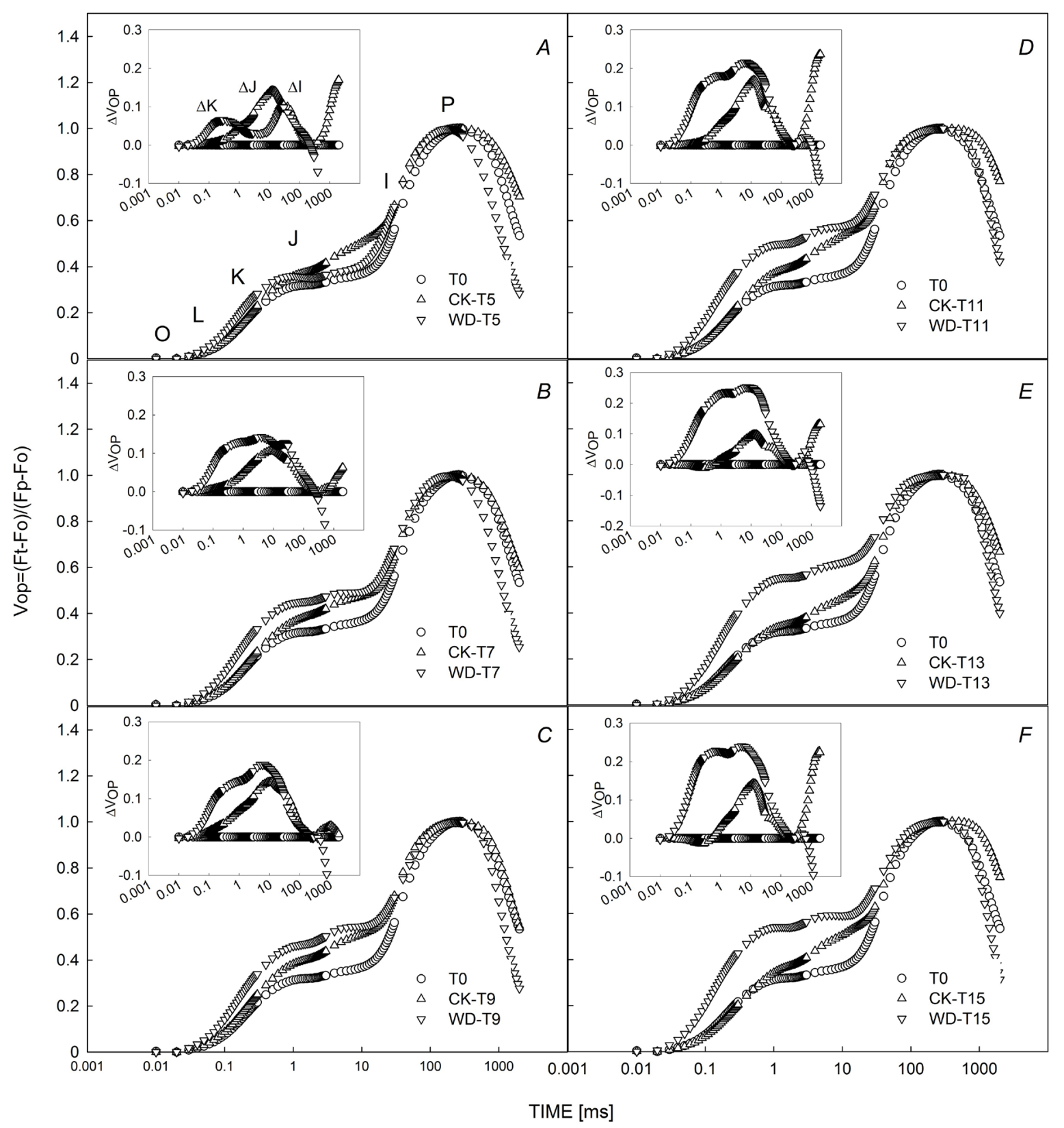

Fig. 2. Changes in the shape of the chlorophyll (Chl) $a$ fluorescence transient curves of maize leaves under continuous WD stress. The large figures $A, B, C, D, E$, and $F$ represent the changes of $\mathrm{V}_{\mathrm{OP}}$ values after $5,7,9,11,13$, and $15 \mathrm{~d}$ of WD stress, respectively. Small inner plots within each graph represent $\Delta \mathrm{V}_{\mathrm{OP}}$ of the corresponding treatment day. $\mathrm{V}_{\mathrm{OP}}$ represents Chl $a$ fluorescence transient curves double normalized between the two fluorescence extremes, $\mathrm{O}\left(\mathrm{F}_{\mathrm{O}}\right)$ and $\mathrm{P}\left(\mathrm{F}_{\mathrm{M}}\right)$ phase: $\mathrm{V}_{\mathrm{OP}}=\left(\mathrm{F}_{\mathrm{T}}-\mathrm{F}_{\mathrm{O}}\right) /\left(\mathrm{F}_{\mathrm{M}}-\mathrm{F}_{\mathrm{O}}\right)$; based on $\mathrm{V}_{\mathrm{OP}}$, $\Delta \mathrm{V}_{\mathrm{OP}}=\mathrm{V}_{\mathrm{OP}}$ (treatment) $-\mathrm{V}_{\mathrm{OP}}$ (control), showing the steps of $\mathrm{L}(0.15 \mathrm{~ms}), \mathrm{K}(0.3 \mathrm{~ms}), \mathrm{J}(0.45 \mathrm{~ms})$, and I $(30 \mathrm{~ms})$ were obtained as periodic differences. L, K, J, and I represent the L $(0.15 \mathrm{~ms})$-step, K $(0.3 \mathrm{~ms})$-step, J $(0.45 \mathrm{~ms})$-step, and I (30 ms)-step of the Chl $a$ fluorescence transient curves, respectively. CK - control; WD - water-deficit stress. Data are the means of four replicates.

especially from the T7 (Fig. 3A,B).

Changes in fluorescence parameters are presented in Table 2. Compared to corresponding CK, the $\varphi_{\text {Po }}, \varphi_{\text {Eo }}$, $\varphi_{\mathrm{Ro}}$, and $\psi_{\mathrm{O}}$ decreased in the WD group. In contrast, the $\mathrm{TR}_{0} / \mathrm{RC}$ and $\mathrm{ABS} / \mathrm{RC}$ increased, and were still higher than that corresponding to $\mathrm{CK}$ treatments. Among these parameters, the biggest change was found in $\mathrm{PI}_{\mathrm{ABS}}$, the performance index based on absorption of light energy, which decreased 5.7-fold at T15 of WD stress. However, the parameters did not change significantly in the CK group (Table 2).

Effect of WD stress on transcript levels of photosynthesis genes: Changes in the transcript levels of $p s b A$, $p s b B, p s b C, p s b P, p s a A, p s a B, r b c L, r b c S, c a b$, and $r c a$ became more obvious with increasing WD duration (Fig. 4). The expression of $p s b B$, psbP, psaA, psaB, and $c a b$ 


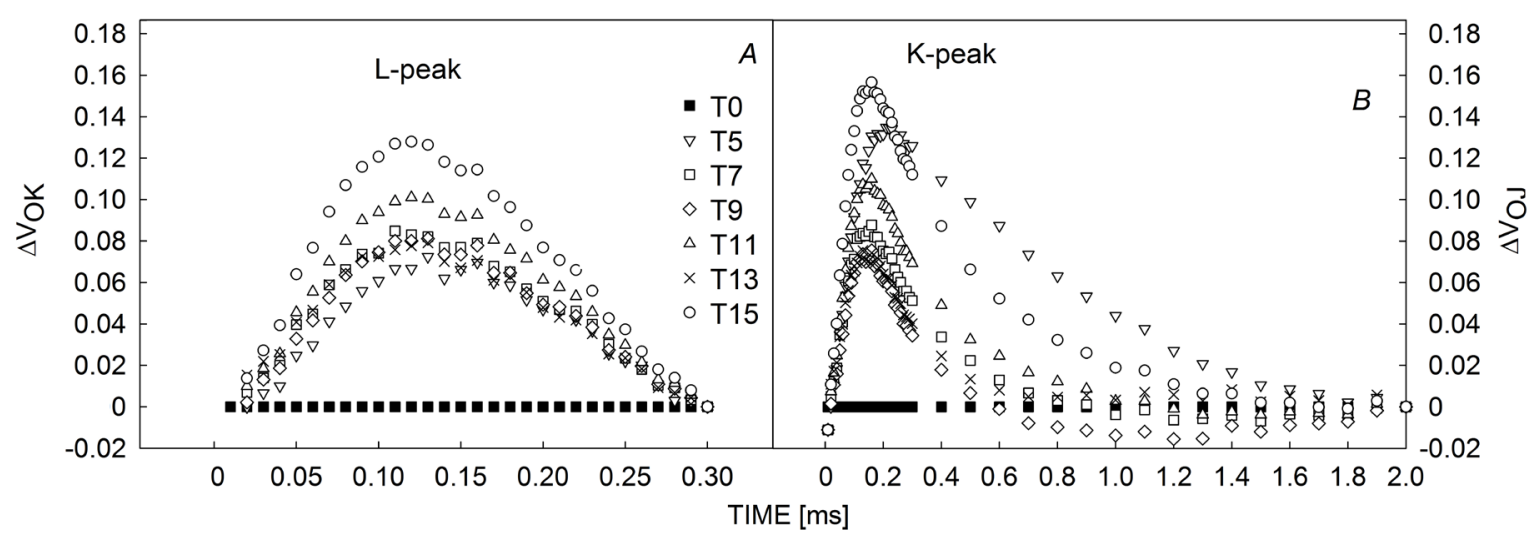

Fig. 3. $\triangle \mathrm{V}_{\mathrm{OK}}(A)$ and $\triangle \mathrm{V}_{\mathrm{OJ}}(B)$ in water-deficit stress group at different treatment times. The relative fluorescence between step $\mathrm{F}_{\mathrm{O}}$ and $\mathrm{F}_{300 \mathrm{u}}: \mathrm{W}_{\mathrm{OK}}=\left(\mathrm{F}_{\mathrm{T}}-\mathrm{F}_{\mathrm{O}}\right) /\left(\mathrm{F}_{\mathrm{K}}-\mathrm{F}_{\mathrm{O}}\right)$, and between $\mathrm{F}_{\mathrm{O}}$ and $\mathrm{F}_{\mathrm{J}}: \mathrm{W}_{\mathrm{OJ}}=\left(\mathrm{F}_{\mathrm{T}}-\mathrm{F}_{\mathrm{O}}\right) /\left(\mathrm{F}_{\mathrm{J}}-\mathrm{F}_{\mathrm{O}}\right)$ were normalized and displayed as $\Delta \mathrm{W}_{\mathrm{OK}}=\mathrm{W}_{\mathrm{OK}}(\mathrm{WD})-\mathrm{W}_{\mathrm{OK}}(\mathrm{CK})$ and $\Delta \mathrm{W}_{\mathrm{OJ}}=\mathrm{W}_{\mathrm{OJ}}(\mathrm{WD})-\mathrm{W}_{\mathrm{OJ}}(\mathrm{CK})$ at different treatment times, which made the L-band (at about $120-150 \mu \mathrm{s}$ ) and K-band (at about 200-300 $\mu$ s) visible, respectively. CK - control; WD - water-deficit stress. Data are the means of four replicates.

Table 2. Changes in Chl $a$ fluorescence transient parameters in dark-adapted maize plants under continuous water deficit conditions in maize leaves. All parameters are deduced from the OJIP-test analysis conducted on potted plants in maize ear leaves at 11:00-11:30 $\mathrm{h}$. See Table 1S for the meaning of the symbols and the parameters. Data are the means \pm standard deviation (SD) of four replicates. * and ${ }^{* *}$ represent significant differences between control and water-deficit stress treatments according to Duncan's multiple range test at $p<0.05$ and $p<0.01$, respectively.

\begin{tabular}{|c|c|c|c|c|c|c|c|c|c|}
\hline \multicolumn{2}{|c|}{ Treatment } & \multirow{2}{*}{$\frac{\varphi_{\mathrm{P}_{\mathrm{O}}}}{0.72 \pm 0.01}$} & \multirow{2}{*}{$\begin{array}{l}\varphi_{\text {Eo }} \\
0.48 \pm 0.02\end{array}$} & \multirow{2}{*}{$\begin{array}{l}\varphi_{\mathrm{Ro}} \\
0.31 \pm 0.02\end{array}$} & \multirow{2}{*}{$\frac{\psi_{\mathrm{O}}}{0.66 \pm 0.03}$} & \multirow{2}{*}{$\frac{\mathrm{ABS} / \mathrm{RC}}{3.23 \pm 0.47}$} & \multirow{2}{*}{$\frac{\mathrm{TR}_{\mathrm{o}} / \mathrm{RC}}{2.31 \pm 0.31}$} & \multirow{2}{*}{$\begin{array}{l}\mathrm{PI}_{\mathrm{ABS}} \\
1.54 \pm 0.18\end{array}$} & \multirow{2}{*}{$\begin{array}{l}\mathrm{DI}_{\mathrm{o}} / \mathrm{RC} \\
0.92 \pm 0.17\end{array}$} \\
\hline 0 & CK & & & & & & & & \\
\hline \multirow[t]{2}{*}{ T5 } & CK & $0.76 \pm 0.02$ & $0.45 \pm 0.02$ & $0.25 \pm 0.02$ & $0.60 \pm 0.03$ & $2.73 \pm 0.35^{*}$ & $2.07 \pm 0.20^{*}$ & $1.73 \pm 0.4$ & $0.66 \pm 0.15^{*}$ \\
\hline & WD & 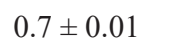 & 3 & & 05 & 3 & 7 & & $1.17 \pm 0.16$ \\
\hline \multirow[t]{2}{*}{$\mathrm{T} 7$} & $\mathrm{CK}$ & 02 & 3 & & 0.59 & 2.83 & & & $.12^{*}$ \\
\hline & WD & & $5^{*}$ & & 0. & 3.79 & & & 32 \\
\hline \multirow[t]{2}{*}{ T9 } & $\mathrm{CK}$ & 074 & 047 & 0 & & 2.8 & & & 0.75 \\
\hline & WD & - & $0.34 \pm$ & 0.22 & 0. & 3. & & $0^{* *}$ & .2 \\
\hline \multirow[t]{2}{*}{ T11 } & $\mathrm{CK}$ & $075+$ & 044 & 0 & $0.58=$ & & & 1.62 & $0.65 \pm 0.07$ \\
\hline & WD & 0.01 & 0.06 & 0.13 & 0. & & & & 1.2 \\
\hline \multirow[t]{2}{*}{$\mathrm{T} 13$} & CK & $0.75=$ & $0.48=$ & $0.28=$ & 0.63 & 2.66 & 2.01 & 1.97 & $0.66 \pm 0.11^{* *}$ \\
\hline & WD & $0.68=$ & $0.29 \pm$ & $0.18 \pm 0.06^{*}$ & & & & $0.46 \pm 0.26^{* *}$ & $1.12 \pm 0.22$ \\
\hline \multirow[t]{2}{*}{$\mathrm{T} 15$} & CK & $0.75 \pm 0$ & $0.46 \pm 0$ & $0.27 \pm 0.01$ & $0.61 \pm 0.02$ & $2.48 \pm 0.20^{* *}$ & $1.87 \pm 0.13^{* *}$ & $1.92 \pm 0.42$ & $0.61 \pm 0.07^{* *}$ \\
\hline & WD & $0.64 \pm 0.02^{*}$ & $0.28 \pm 0.03^{*}$ & $0.18 \pm 0.02^{*}$ & $0.45 \pm 0.04^{*}$ & $4.15 \pm 0.28$ & $2.64 \pm 0.12$ & $0.34 \pm 0.12^{* *}$ & $1.51 \pm 0.18$ \\
\hline
\end{tabular}

were not significantly different between T5 and T7 under WD compared with the corresponding CK. However, expression declined for the seven photosynthesis-related genes under WD, particularly, after T11. For example, transcript levels of $p s b A, p s b B, p s b C, p s b P, p s a A, p s a B$, and $c a b$ were lower by $23.8,12.8,23.5,10.4,0.3,9.9$, and $2.2 \%$, respectively, compared with the corresponding CK at T11. At T13, transcript levels of these genes were also significantly reduced compared with the corresponding $\mathrm{CK}$. The expression of $r b c L$ and $r b c S$ significantly increased by 21.2 and $14.6 \%$, respectively, at T13; and significantly increased by 6.7 and $49.7 \%$, respectively, at T15. However, $r b c S$ was down-regulated compared with $\mathrm{CK}$ at early stages of WD and there were no significant changes of $r b c L$ at $\mathrm{T} 5, \mathrm{~T} 7$, and $\mathrm{T} 9$. Interestingly, $r c a$ decreased by $29.9,22.1$, and $39.6 \%$ at $\mathrm{T} 5, \mathrm{~T} 7$, and $\mathrm{T} 9$, respectively, compared with the corresponding CK. However, the expression of $r c a$ was higher by 11.9, 1.3, and $9.3 \%$ at $\mathrm{T} 11, \mathrm{~T} 13$, and $\mathrm{T} 15$, respectively, compared with the corresponding $\mathrm{CK}$.

\section{Discussion}

WD stress inhibits electron transport, which in turn impacts photosynthesis. Nonstomatal mechanism may play a greater role in inhibiting $P_{\mathrm{N}}$ (Guha et al. 2013). In this study, the reductions in $P_{\mathrm{N}}$ under adverse conditions were mainly due to changes in $g_{\mathrm{s}}$ and $C_{\mathrm{i}}$ (Ye et al. 2008). When both $C_{\mathrm{i}}$ and $g_{\mathrm{s}}$ decrease simultaneously, stomatal limitations are crucial for $P_{\mathrm{N}}$. In contrast, if $C_{\mathrm{i}}$ increases or does not change when $g_{\mathrm{s}}$ decreases, nonstomatal mechanisms become the main limiting factor in determining $P_{\mathrm{N}}$ (Dias 


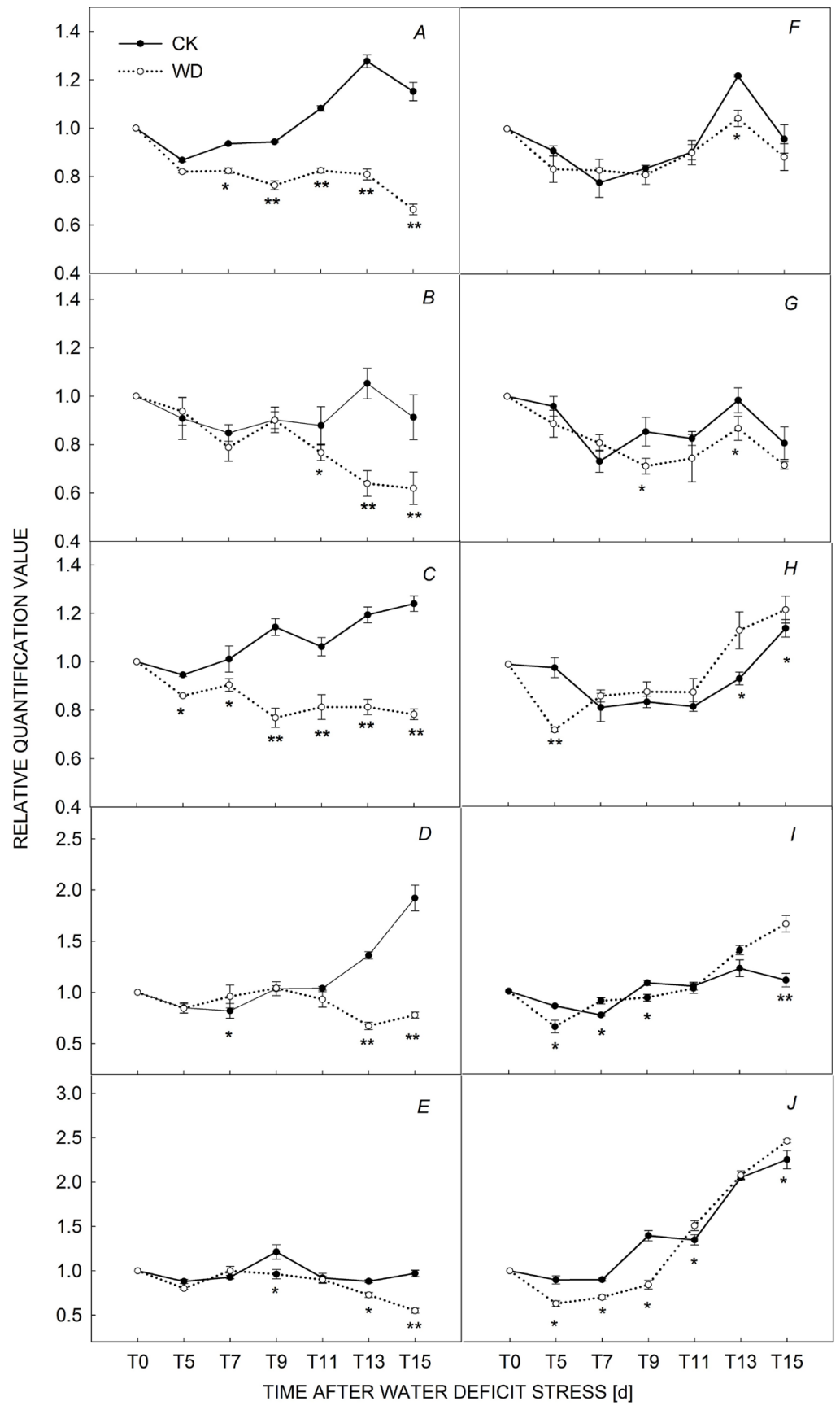

Fig. 4. The expression of the photosynthesis related genes $p s b A(A), p s b B(B), p s b C(C), p s b P$ $(D), c a b(E), p s a A(F), p s a B(G), r b c L(H), r b c S$ $(I)$, and $r c a(J)$ for maize plants after $0,5,7,9,11$, 13 , and $15 \mathrm{~d}$ of water-deficit stress. T0, T5, T7, $\mathrm{T} 9, \mathrm{~T} 11, \mathrm{~T} 13$, and $\mathrm{T} 15$ represent $0,5,7,9,11,13$, and $15 \mathrm{~d}$ after of water-deficit stress, respectively. ${ }^{*}$ and ${ }^{* *}$ represent significant differences between control and water-deficit stress treatments according to Duncan's multiple range test at $p<0.05$ and $p<0.01$, respectively. CK - control; WD - water-deficit stress. Data are the means \pm standard deviation (SD) of three replicates. et al. 2010). In this study, under long-term WD stress, photosynthetic disturbances may be mainly attributed to nonstomatal limitations.

Chl $a$ fluorescence can be used to evaluate the impact of stress factors on photosynthesis (Gomes et al. 2012) and it is sensitive to drought stress (Shao et al. 2010). Research has shown that drought stress affected OJIP transients and related parameters in many plants (Redillas et al. 2011, Kalaji et al. 2014). In the present study, the J-step and I-step gradually increased (Fig. 3) along with increasing duration of drought, which might cause the accumulation of reduced $\mathrm{Q}_{\mathrm{A}}$ and consequently drastically decreased electron transport after $\mathrm{Q}_{\mathrm{A}}$, which was also confirmed by decreased $\varphi_{\mathrm{Eo}}, \varphi_{\mathrm{Po}}$, and $\psi_{\mathrm{O}}$ in our study. These OJIP-related parameters are indicators of photoinhibition and the degree of injury to PSII ( Zhang et al. 2015, Ghotbi-Ravandi et al. 2014). Decreases in $\varphi_{\mathrm{Eo}}, \varphi_{\mathrm{Po}}$, and $\psi_{\mathrm{O}}$, suggested that WD stress led to photoinhibitory impairment, which mainly occurred at the donor side of PSII of the photosynthetic electron transport chain because the reduction end acceptors of PSI were seriously damaged. Reduction of the photosynthetic electron transport chain under drought conditions resulted in a decrease of $\mathrm{PI}_{\mathrm{ABS}}$. This indicated that the potential PSII activity, photosynthesis photoinhibition, and PSII function were damaged (Oukarroum et al. 2009). The L peaks $(120-150 \mu \mathrm{s})$ were sharper with increasing duration of the treatment under drought, which might indicate that the stability and structure of PSII RCs were affected 
(Zhang 1999). ABS/RC, $\mathrm{TR}_{\mathrm{o}} / \mathrm{RC}$, and $\mathrm{DI}_{\mathrm{o}} / \mathrm{RC}$ increased under WD, indicating that partial RCs were inactive and efficiency per RC was enhanced (Redillas et al. 2011, Guha et al. 2013, Meng et al. 2016). This result may represent a self-protection mechanism of maize leaves, which helped plants resist drought stress and maintain growth under water stress.

WD stress could also induce or increase expression of PSII proteins or genes, which are involved in various pathways of the photosynthetic process (Yuan et al. 2005, Duan et al. 2006, Guha et al. 2013, Chen et al. 2016). Therefore, we also analyzed the transcript levels of photosynthesis-related genes to verify the photosynthetic changes under WD during the reproductive phase. The primary light-driven photosynthetic reactions are carried out in the thylakoid membrane in PSII and PSI (Ferreira et al. 2004). In this study, we found that the expression of ps $b B, p s b C$ (encoding the light-harvesting proteins CP47 and CP43), and $c a b$ (encoding the light-harvesting $\mathrm{Chl} a / b$ binding protein) genes were down-regulated under WD stress, consistent with previous studies (Seki et al. 2002, Yuan et al. 2005, Živčák et al. 2013, Muhammad Salman et al. 2016). The results suggested that the light-harvesting process might be harmed after moderate drought stress, and reduced expression of these genes may also explain the changes in $\varphi_{\mathrm{Po}}$. Decreased electron transfer activities may be the main factor leading to PSII instability (Li et al. 2016). The expression of $p s b A$ (encoding D1) was down-regulated, indicating that electron transport and PSII stability were affected (Yuan et al. 2005, Liu et al. 2006). $\varphi_{\text {Ro }}$ was an important indicator that could reflect the status of the reduction end acceptors of PSI (Strasser et al. 1995). Decreased $\varphi_{\text {Ro }}$ or damage to PSII function under WD stress might be an indirect result of decreased expression of psa $A$ and $p s a B$ (which encode the PSI reaction center proteins (Tang et al. 2002). In addition, the significantly decreased $p s b P$ [encoding extrinsic nuclear-encoded subunits of the PSII oxygen-evolving complex (OEC)] expression at the late drought stage indicated that the OEC suffered serious injuries. Simultaneously, K band is an indicator of OEC damage (Oukarroum et al. 2009, Zhang et al. 2015), and in this study, a positive $\mathrm{K}$ band $(200-300 \mu \mathrm{s})$ of the Chl $a$ fluorescence curve was also found after prolonged drought stress. Decreased $p s b P$ as well as increased $\mathrm{K}$ peak and $\mathrm{L}$ peak, suggested that the balance of electron transport between the donor and acceptor side of PSII was damaged.

Plants have developed several mechanisms to protect the photosynthetic apparatus from injury. For example, it has been reported that increased levels of $r b c L$ and $r b c S$ compensate for the loss of oxidative stress damage due to WD, maintaining photosynthesis and preventing stressrelated damage in rice plants (Xiong et al. 2010). In this study, significantly increased expression of $r b c L$ and $r b c S$ were observed at T13 and T15 in WD plants, which was consistent with results from Xu et al. (2013) in Kentucky bluegrass plants and Fu et al. (2007) in rice under drought stress. Maintaining higher Rubisco activity is necessary to sustain higher $P_{\mathrm{N}}$ (Zhang et al. 2015). Up-regulation of $r b c L$ and $r b c S$ may help to maintain photosynthesis and prevent damage due to drought. Interestingly, in the present study, $P_{\mathrm{N}}$ still decreased rapidly despite these adaptations, indicating that long-term water stress resulted in a serious damage to photosynthesis. However, some studies have reported that these two genes are downregulated under drought stress (Bartholomew et al. 1991, Pelloux et al. 2001, Hayano-Kanashiro et al. 2009), which is not consistent with our results. This discrepancy may be due to differences in drought severity and duration. The gene rca regulates Rubisco (Portis 1995). Increased expression of $r c a$ at T15 in WD plants might serve to alleviate damage of Rubisco by drought stress (Ji et al. 2012). However, $r c a$ expression was lower in WD plants at T5, T7, and T11, similar to results of other plant species under drought stress (Pelloux et al. 2001). These differing effects of drought on rca expression may occur due to species differences and variation in relative stress intensity (Xu et al. 2013).

Conclusion: In summary, under long-term WD stress, nonstomatal limitations may be the primary cause of photosynthetic disturbances. Fluorescence parameters combined with transcript levels of photosynthesis-related genes indicated that down-regulation of light-harvesting and electron transport during the photosynthesis process might be caused by the low expression levels of $p s b A$, $p s a A, p s a B, p s b B, p s b C$, and $c a b$, which in turn impact the photosynthesis. However, higher transcript levels of $r b c L$ and $r b c S$ in the later stages of WD stress might be associated with maintenance of photosynthetic capacity under long-term WD stress. Despite these adaptations, the drop-offs in $P_{\mathrm{N}}$ and biomass were not prevented, indicating that the damage caused by WD in this study was beyond the repair ability of plants.

\section{References}

Anjum S.A., Tanveer M., Ashraf U. et al.: Effect of progressive drought stress on growth, leaf gas exchange, and antioxidant production in two maize cultivars. - Environ Sci. Pollut. R. 23: 17132-17141, 2016.

Bartholomew D.M., Bartley G.E., Scolnik P.A.: Abscisic acid control of $r b c S$ and cab transcription in tomato leaves. - Plant Physiol. 96: 291-296, 1991.

Chen Y.E., Liu W.J., Su Y.Q. et al.: Different response of photosystem II to short and long term drought stress in Arabidopsis thaliana. - Physiol. Plantarum 158: 225-235, 2016.

Daryanto S., Wang L., Jacinthe P.: Global synthesis of drought effects on maize and wheat production. - PLoS ONE 11: e156362, 2016.

Dias M C, Brüggemann W.: Limitations of photosynthesis in Phaseolus vulgaris under drought stress: gas exchange, chlorophyll fluorescence and Calvin cycle enzymes. - Photosynthetica 48: 96-102, 2010.

Duan H.G., Yuan S., Liu W.J. et al.: Effects of exogenous spermidine on photosystem II of wheat seedlings under water stress. - J. Integr. Plant Biol. 48: 920-927, 2006.

Ferreira K.N., Iverson T.M., Maghlaoui K. et al.: Architecture of the photosynthetic oxygen-evolving center. - Science 303: 1831-1838, 2004.

Fu B., Xiong J., Zhu L. et al.: Identification of functional candidate genes for drought tolerance in rice. - Mol. Genet. Genomics 278: 599-609, 2007. 
Ghotbi-Ravandi A.A., Shahbazi M., Shariati M. et al.: Effects of mild and severe drought stress on photosynthetic efficiency in tolerant and susceptible Barley (Hordeum vulgare L.) genotypes. - J. Agron. Crop Sci. 200: 403-415, 2014.

Gilbert M.E., Medina V.: Drought adaptation mechanisms should guide experimental design. - Trends Plant Sci. 21: 639-647, 2016.

Goltsev V., Zaharieva I., Chernev P. et al.: Drought-induced modifications of photosynthetic electron transport in intact leaves: analysis and use of neural networks as a tool for a rapid noninvasive estimation. - BBA - Bioenergetics 1817: 1490-1498, 2012.

Gomes M.T.G., da Luz A.C., dos Santos M.R. et al.: Drought tolerance of passion fruit plants assessed by the OJIP chlorophyll $a$ fluorescence transient. - Sci. Hortic.-Amsterdam 142: 49-56, 2012.

Guha A., Sengupta D., Reddy A.R.: Polyphasic chlorophyll $a$ fluorescence kinetics and leaf protein analyses to track dynamics of photosynthetic performance in mulberry during progressive drought. - J. Photoch. Photobio. B. 119: 71-83, 2013.

Hansen S., Clay S.A., Clay D.E. et al.: Landscape features impact on soil available water, corn biomass, and gene expression during the late vegetative stage. - Plant Genome-US 6: 547$562,2013$.

Hayano-Kkanashiro C., Ibarra-Laclette E., Herrera-Estrella L. et al.: Analysis of gene expression and physiological responses in three mexican maize landraces under drought stress and recovery irrigation. - PLoS ONE 4: e7531, 2009.

Ifuku K., Yamamoto Y., Ono T. et al.: PsbP protein, but not PsbQ protein, is essential for the regulation and stabilization of photosystem II in higher plants. - Plant Physiol. 139: 11751184, 2005.

Ji K., Wang Y., Sun W. et al.: Drought-responsive mechanisms in rice genotypes with contrasting drought tolerance during reproductive stage. - J. Plant Physiol. 169: 336-344, 2012.

Jiang C.D., Shi L., Gao H.Y. et al.: Development of photosystems 2 and 1 during leaf growth in grapevine seedlings probed by chlorophyll $a$ fluorescence transient and $820 \mathrm{~nm}$ transmission in vivo. - Photosynthetica 44: 454-463, 2006.

Kalaji H.M., Oukarroum A., Alexandrov V. et al.: Identification of nutrient deficiency in maize and tomato plants by in vivo chlorophyll $a$ fluorescence measurements. - Plant Physiol. Bioch. 81: 16-25, 2014.

Kakumanu A., Ambavaram M.M.R., Klumas C. et al.: Effects of drought on gene expression in maize reproductive and leaf meristem tissue revealed by RNA-Seq. - Plant Physiol. 160: 846-867, 2012.

Lazár D.: The polyphasic chlorophyll $a$ fluorescence rise measured under high intensity of exciting light. - Funct. Plant Biol. 33: 9-30, 2006.

Li H., Xu H., Zhang P. et al:: High temperature effects on D1 protein turnover in three wheat varieties with different heat susceptibility. - Plant Growth Regul. 81: 1-9, 2016.

Lin Z.H., Chen L.S., Chen R.B. et al.: $\mathrm{CO}_{2}$ assimilation, ribulose1,5-bisphosphate carboxylase/oxygenase, carbohydrates and photosynthetic electron transport probed by the JIP-test, of tea leaves in response to phosphorus supply. - BMC Plant Biol. 9: 43, 2009.

Liu J., Folberth C., Yang H. et al.: A global and spatially explicit assessment of climate change impacts on crop production and consumptive water use. - PLoS ONE 8: e57750, 2012.

Liu W.J., Yuan S., Zhang N.H. et al.: Effect of water stress on photosystem 2 in two wheat cultivars. - Biol. Plantarum 50: 597-602, 2006.

Long S., Marshall-Colon A., Zhu X.G.: Meeting the global food demand of the future by engineering crop photosynthesis and yield potential. - Cell 161: 56-66, 2015.

Meng L.L., Song J.F., Wen J. et al.: Effects of drought stress on fluorescence characteristics of photosystem II in leaves of Plectranthus scutellarioides. - Photosynthetica 54: 414-421, 2016.

Mo Y., Yang R., Liu L. et al:: Growth, photosynthesis and adaptive responses of wild and domesticated watermelon genotypes to drought stress and subsequent re-watering. Plant Growth Regul. 79: 229-241, 2016.

Muhammad Salman H., Zhang C., Pervaiz T. et al:: Gene regulation mechanism in drought-responsive grapevine leaves as revealed by transcriptomic analysis. - BioRxiv. DOI: org/10.1101/065136, 2016.

Oukarroum A., Schansker G., Strasser R.J.: Drought stress effects on photosystem I content and photosystem II thermotolerance analyzed using $\mathrm{Chl}$ a fluorescence kinetics in barley varieties differing in their drought tolerance. - Physiol. Plantarum 137: 188-199, 2009.

Panda D., Rao D.N., Sharma S.G. et al.: Submergence effects on rice genotypes during seedling stage: probing of submergence driven changes of photosystem 2 by chlorophyll $a$ fluorescence induction OJIP transients. - Photosynthetica 44: 69-75, 2006.

Parry M.A.J., Andralojc P.J., Khan S. et al.: Rubisco activity: effect of drought stress. - Ann. Bot.-London 89: 833-839, 2002.

Pelloux J., Jolivet Y.V., Banvoy J. et al.: Changes in Rubisco and Rubisco activase gene expression and polypeptide content in Pinus halepensis M. Subjected to ozone and drought. - Plant Cell Environ. 24: 123-131, 2001.

Portis A.R.: The regulation of Rubisco by Rubisco activase. - J. Exp. Bot. 46: 1285-1291, 1995.

Redillas M.C.F.R., Strasser R.J., Jeong J.S. et al:: The use of JIP test to evaluate drought-tolerance of transgenic rice overexpressing OsNAC10. - Plant Biotechnol. Rep. 5: 169-175, 2011.

Sarkar R.K., Ray A.: Submergence-tolerant rice withstands complete submergence even in saline water: Probing through chlorophyll $a$ fluorescence induction OJIP transients. Photosynthetica 54: 275-287, 2016.

Schansker G., Tóth S.Z., Strasser R.J.: Methylviologen and dibromothy moquinone treatments of pea leaves reveal the role of photosystem I in the Chl a fluorescence rise OJIP. BBA-Bioenergetics 1706: 250-261, 2005.

Seki M., Narusaka M., Ishida J. et al.: Monitoring the expression profiles of 7000 Arabidopsis genes under drought, cold and high-salinity stresses using a full-length cDNA microarray. Plant J. 31: 279-292, 2002.

Shao R., Wang K., Shangguan Z.: Cytokinin-induced photosynthetic adaptability of Zea mays L. To drought stress associated with nitric oxide signal: probed by ESR spectroscopy and fast OJIP fluorescence rise. - J. Plant Physiol. 167: 472-479, 2010.

Strasser R.J., Srivastava A., Govindjee.: Polyphasic chlorophyll alpha fluorescence transient in plants and cyanobacteria. Photochem. Photobiol. 61: 32-42, 1995.

Strasser R.J., Tsimilli-Michael M., Qiang S. et al.: Simultaneous in vivo recording of prompt and delayed fluorescence and $820-\mathrm{nm}$ reflection changes during drying and after rehydration of the resurrection plant Haberlea rhodopensis. - BBABioenergetics 1797: 1313-1326, 2010.

Strasser R.J., Tsimillimichael M., Srivastava A.: Analysis of the chlorophyll $a$ fluorescence transient. - In: Papageorgiou G.C., Govindjee (ed.): Chlorophyll $a$ Fluorescence. - Advances in Photosynthesis and Respiration. Pp. 321-362. Springer, Dordrecht 2004.

Strasser R.J., Tsimilli-Michae M., Dangre D. et al.: Biophysical 
phenomics reveals functional building blocks of plants systems biology: a case study for the evaluation of the impact of mycorrhization with Piriformospora indica. - In: Varma A, Oelmüller R. (ed.): Advanced Techniques in Soil Microbiology, Vol. 11. Soil Biology. Pp. 319-341. Springer, Berlin Heidelberg 2007.

Stirbet A.: On the relation between the Kautsky effect (chlorophyll $a$, fluorescence induction) and photosystem II: basics and applications of the OJIP fluorescence transient. - J. Photoch. Photobio. B 104: 236-257, 2011.

Syuhada N., Jahan M.S., Khandaker M.M. et al.: Application of copper increased corn yield through enhancing physiological functions. - Aust. J. Basic Appl. Sci. 8: 282-286, 2014.

Tang Q.X., Ni Z.L., Wei J.M.: Effect of chlorophyll-protein complex I deficiency on the physiological character of a Chlamydomonas reinhardtii mutant. - Photosynthetica 40: 529-534, 2002

Xiong J.H., Fu B.Y., Xu H.X. et al.: Proteomic analysis of PEGsimulated drought stress-responsive proteins of rice leaves using a pyramiding rice line at the seedling stage. - Bot. Stud. 51: $137-145,2010$

Xu L., Yu J., Han L. Huang B.: Photosynthetic enzyme activities and gene expression associated with drought tolerance and post-drought recovery in kentucky bluegrass. - Environ. Exp. Bot. 89: 28-35, 2013.

Ye Z.P., Suggett D.J., Robakowski P. et al.: A mechanistic model for the photosynthesis-light response based on the photosynthetic electron transport of photosystem II in C3 and C4 species. - New Phytol. 199: 110-120, 2013.

Ye Z.P., Yu Q.: A coupled model of stomatal conductance and photosynthesis for winter wheat. - Photosynthetica 46: 637 640, 2008.

Yi X., Hargett S.R., Liu H., Frankel L.K. et al.: The PsbP protein is required for photosystem II complex assembly/stability and photoautotrophy in Arabidopsis thaliana. - J. Biol. Chem. 282: 24833-24841, 2007.

Yuan S., Liu W.J., Zhang N.H. et al.: Effects of water stress on major photosystem II gene expression and protein metabolism in barley leaves. - Physiol. Plantarum 125: 464-473, 2005.

Zhang S.R.: A discussion on chlorophyll fluorescence kinetics parameters and their significance. - Chinese Bull. Bot. 16: 444-448, 1999. [in Chinese]

Zhang Y. J., Xie Z.K., Zhao X.Y. et al.: Effects of water stress on photosynthetic characteristics, chlorophyll fluorescence, and dry matter of Oriental lilies. - J. Desert Res. 31: 884-888, 2011.

Zhang R., Zhang X., Camberato J. et al:: Photosynthetic performance of maize hybrids to drought stress. - Russ. J. Plant Physl+ 62: 788-796, 2015.

Zhao L.F., Li C.H., Liu T.X. et al.: Genotypic responses and physiological mechanisms of maize (Zea mays L.) to high temperature stress during flowering. - Acta Agron. Sin. 38: 857-864, 2013.

Zheng S.H., Yan C.R.: The ecophysiological and morphological characteristics of maize in seedling stage under water stress. Acta Ecol. Sin. 26: 1138-1143, 2006.

Živčák M., Breštić M., Balatova Z. et al.: Photosynthetic electron transport and specific photoprotective responses in wheat leaves under drought stress. - Photosynth. Res. 117: 529-546, 2013.

(C) The authors. This is an open access article distributed under the terms of the Creative Commons BY-NC-ND Licence. 